\title{
The Influence of the Change
}

\section{Frequency of Director of Manufacturing Management on the Quality Management}

\section{-Take Anhui Province as an Example}

\author{
Jingjing Luo ${ }^{1}$, Gordon G. Liu ${ }^{1}$, Weijun Tian ${ }^{2}$ \\ ${ }^{1}$ China Pharmaceutical University, Nanjing, China \\ ${ }^{2}$ School of Management, Shanghai University, Shanghai, China \\ Email: luojj_j@163.com, ^gordonliu@nsd.pku.edu.cn, tianweijun55@163.com
}

How to cite this paper: Luo, J.J., Liu, G.G. and Tian, W.J. (2019) The Influence of the Change Frequency of Director of Manufacturing Management on the Quality Management. Open Journal of Social Sciences, 7, 63-74.

https://doi.org/10.4236/jss.2019.79006

Received: August 11, 2019

Accepted: September 6, 2019

Published: September 9, 2019

Copyright $\odot 2019$ by author(s) and Scientific Research Publishing Inc. This work is licensed under the Creative Commons Attribution International License (CC BY 4.0).

http://creativecommons.org/licenses/by/4.0/ (c) (i) Open Access

\begin{abstract}
Based on the survey data from questionnaire of Quality Management of Pharmaceutical Production Enterprises in Anhui Province, this research examines the relationship between the change frequency of production director and GMP inspection results of pharmaceutical manufacturers by adopting OLS model and Logit model. We find that director of manufacturing management plays a direct role in enterprise production management as senior administrator. If director of manufacturing management changes more times, the enterprise's drug production management will lose persistent stability. As a result, the quality of drug production is affected. Without ability to produce high-quality drugs, the GMP inspection results of pharmaceutical enterprises are poor. Thus, this paper suggests that in daily drug quality supervision, enterprises that frequently change director of manufacturing management should be paid more attention to, and we should increase the frequency of examination, so as to reasonably allocate regulatory resources and carry out targeted supervision.
\end{abstract}

\section{Keywords}

Change Frequency, Director of Manufacturing Management, Quality Management, OLS Model, Logit Model

\section{Introduction}

Good Manufacturing Practice (GMP) [1] is an important means to ensure the quality and safety of drug production. In 2011, the ministry of health released 
the revised version of GMP in 2010. It stipulates that the important person of drug production at least shall include the director of the enterprise, director of manufacturing management, director of quality management and authorized person of quality, among which director of manufacturing management is one of the key personnels in GMP.

Director of manufacturing management should be equipped with detailed qualifications and responsibilities in GMP. It mainly refers to audit and approve the documents of products' technology procedure, operation procedures; supervise the sanitation condition of factory; ensure the key equipment has been confirmed; ensure finishing the validation of production technology; ensure all related persons in enterprise are trained by pre-job training and on-job training, adjust training content according to actual demands; approve and supervise consigned manufacture; ensure and monitor the storage condition of material and goods; save the record; supervise the implement condition of this Regulation; monitor the factors influencing the quality of the products.

In the GMP, director of manufacturing management takes important responsibilities in understanding of drug production documents, controlling of production environment, confirming equipment, training staff, managing material, implementing this Regulation, and keeping the stability of enterprise production system.

At present, drug quality management has evolved into life-cycle management. The development of drug quality management has gone through three stages: pharmaceutical products inspection, quality control into the process of pharmaceutical good's manufacturing and pharmaceutical goods' quality relying on design (contraction of comprehensive quality control system). The quality system should cover all factors affecting pharmaceutical goods' quality, be consistently manufactured in accordance with the registration requirements, and be suitable for their intended use, by minimizing the risks of contamination, cross-contamination and mixups or errors in manufacturing process.

There are many interrelated factors influencing the quality system. ICHQ9 points out that the change of key personnel should be evaluated for the quality risk caused by the change [2]. We find that in ICHQ10 Senior management plays an important role in ensuring and committing appropriate resources (e.g., Personnel equipment), participating in the implementation and maintenance of an effective pharmaceutical quality system, and achieving continual improvement [3]. In addition to direct management, it is also necessary to ensure enterprise' information is communicated and understood at all levels of the organization, and conduct management reviews of the pharmaceutical quality system.

In recent years, China's pharmaceutical production market has been booming. As the data from Ministry of Industry and Information Technology of the People's Republic of China, in 2015, the total output value of the pharmaceutical industry reached 2903.8 billion yuan, with a year-on-year growth of $12.56 \%$. The compound annual growth rate of total output value in the pharmaceutical industry's reached $11.48 \%$ from 2009 to 2015 . By 2020, China will become the 
world's second largest pharmaceutical market after the United States, accounting for 7.5 percent of the global pharmaceutical market by projections [4]. The development of the market brings about the turnover of personnel and the change of personnel is extremely frequent. There is no denying that personnel changes have certain impact on the continuity of quality system. Regulators are aware of the problem. Article 46 of the measures for supervision and administration of drug production stipulates that if the person in charge of quality or production administration of a drug manufacturer changes, the new one shall, within 15 days after the change, submit his/her resume, education certificate and other relevant information to the food and drug supervision and administration department of the province, autonomous region or municipality where he/she is located for the record [5]. Through this measure, the random change of key personnel in drug manufacturing enterprises is restricted to a certain extent.

\section{Literature Review}

Extensive foreign research has demonstrated the impact of senior executive changes on corporate performance and business operating system. It also reveals the mechanism of executive management changes in the organization from multiple perspectives.

Burton, Walsh (1998) [6] and Currie (1998) [7] studied the mechanism of executive personnel change in the organization and its impact on the operating system of the organization. Stewart and Diebold (2017) [8] collected data of 998 enterprises within 6 years and tested the relationship between enterprise size, enterprise financial situation, size of board of directors, salary and senior executive change by empirical methods. Alabdullah et al. (2016) [9] used panel data of listed non-financial companies in Jordan to study the relationship between corporate management, financial management and executive change. Senior executive change has a significant negative impact on financial leverage and business management. At present, domestic researches mainly focus on the impact of the change of senior executives of listed companies on the output of enterprises, but few researches are specific to pharmaceutical manufacturing company. Han Wen (2015) [10] selected the data of gem companies from 2011 to 2013 as samples, established a model and concluded that there was a positive correlation between executive change and negative earnings management. Zhang Wen (2016) [11], Wei Juan (2013) [12] and others all believe that there is a correlation between executive change and company performance and rate of profit.

However, pharmaceutical enterprises with their own specific characteristics, their performance does not directly reflect the quality of pharmaceutical production and the level of business management. Zhu Meng (2018) [13] carried out the research in A Pharmaceutical Company and revealed that, in the process of improving pharmaceutical production quality, how does changing director of manufacturing management affect the entire production system of pharmaceutical enterprises? The detailed are shown in the following aspects: 
Firstly, after changing director of manufacturing management, the new appointee may be unfamiliar with the company's business. Besides, the team unity is weak, and a certain run-in period is needed to reunite the team; All these are easy to lead to more loopholes in management.

Secondly, the relationship between new director of manufacturing management and personnel in other departments is a new twist. In the case of poor communication and coordination with the production support department of the company, the sudden problems in the production process cannot be solved timely and effectively. The lack of tacit cooperation among various departments not only causes production delay and low efficiency, but also increases the probability of unqualified products.

Liu Zhonge (2017) [14] established the model by using the index weight method and believed that the stability of drug production managers should be an important index for Beijing's daily supervision. Qiao Weilin (2016) [15] believes that ensuring the quality of drug production depends on the stable, consistent and continuous controllable production state. To achieve such a state, it is necessary to establish a sound quality management system, not only to ensure the independent, healthy and effective operation of the system, but also to continuously improve and perfect the system. Director of manufacturing management is the implementor of the system construction and the leader of operation monitoring, playing an important role in the operation of key positions such as production, quality, materials, equipment and engineering.

\section{Data Sources and Descriptive Statistics}

Source: data were obtained from questionnaires on the production quality management of drug manufacturing enterprises in 16 prefectures and cities of Anhui Province.

Survey objects and survey methods: drug manufacturing enterprises in the whole province were classified according to their local conditions and types. For example, according to the type of enterprise in a certain city, it can be divided into aseptic preparations, Chinese herbal decoction pieces, non-aseptic preparations, medical oxygen and API. The survey objects were selected by stratified random sampling in proportion, and the whole sampling process was carried out on the corresponding sampling software. And the method of self-filling questionnaire and investigator checking has been used. 230 enterprises were selected and distributed for investigation, and 15 invalid questionnaires were removed to form 215 valid questionnaires. The employees who fill in the questionnaire are mainly from the quality department and the administrative department. In addition, the inspection results (defect items) were matched with the investigated enterprises according to the 2010 GMP certification inspection defect project database of pharmaceutical manufacturing enterprises in Anhui Province.

Survey content: the questionnaire is composed of two parts, 1) the basic characteristics of the enterprise, including the investigated enterprise, contact per- 
son and basic information; 2) questions related to the management of pharmaceutical production, including the characteristic variables of enterprises and the subjective questions answered by enterprises.

Data processing method: Epidata3.1 was used to establish the questionnaire entry database, and we used double-entry check to ensure the data's accuracy for each valid questionnaire. The data was analyzed by multifactor OLS model and Logit model in STATA 10.

Quality control: many quality controlling measures have been adopted, such as the design and demonstration of the investigation scheme, the unified training of investigators, the input and verification of pre-investigation data, etc., with clear requirements to ensure the authenticity of data.

\section{Econometric Model}

\subsection{OLS Regression Model}

For this study, when the quality management level of drug manufacturing enterprises is estimated, the least square method is first used to analyze:

$$
Y=\beta_{0}+\beta_{i} X_{i}+\varepsilon
$$

In Equation (1), $Y$ is the inspection result of the enterprise and it also represents the quality management level of the enterprise. $\beta_{0}$ is the constant term. $i$ represents the coefficient of different influencing factors. $X_{i}$ stands for different influencing factors. $\varepsilon$ is the error term.

\subsection{Logit Model}

The dependent variable in this study, namely whether the enterprise passes the GMP inspection, is a typical 0-1 discrete selection variable. The binary Logit model can better satisfy the study of the related problems of discrete selection variables, so this model is selected for the study. If the dependent variable does not pass the test, then $Z=1$; if it does, then $Z=0$. It is assumed that the probability of $Z=1$ is $P . x_{i}(i=1,2, \ldots, n)$ is the explanatory variable, various factors affecting production management of drugs. $b_{i}(i=1,2, \ldots, n)$ is the regression coefficient of the i-th influencing factor. If $b_{i}$ is positive, it means the $i$ factor has a positive impact on drug production management; if $b_{i}$ is negative, it means it has a negative impact. Logit binary discrete selection model is as follows:

$$
P=F(Z) \frac{1}{1+\mathrm{e}^{-z}}
$$

In formula (1), $Z$ is a linear combination of variables $x_{1}, x_{2}, \ldots, x_{p}$

$$
Z=b_{0}+b_{1} x_{1}+b_{2} x_{2}+\cdots+b_{p} x_{p}
$$

By transforming Equations (2) and (3), the Logit model is represented by the occurrence ratio.

$$
\operatorname{Ln}\left(\frac{P}{1-P}\right)=b_{0}+b_{1} x_{1}+b_{2} x_{2}+\cdots+b_{p} x_{p}+\varepsilon
$$

In Equation (4), $b_{0}$ is a constant term. $b_{i}(i=1,2, \ldots, p)$ is the coefficient of the 
independent variable. $\varepsilon$ is a random error. The values of $b_{0}$ and $b_{i}$ can be estimated by the maximum likelihood estimation method.

\subsection{Variable Setting}

The setting of variables can be divided into two parts: dependent variable and explanatory variable.

\subsubsection{Dependent Variable}

The data of the dependent variable part comes from the inspection database of drug manufacturing enterprises of Anhui Provincial assessment and certification center from 2011 to 2016, which is responsible for the inspection of drug manufacturing enterprises in Anhui Province. According to the requirements, the specific information of the enterprise is anonymized. The inspection standard for enterprises is the "drug production quality management standard" (revised in 2010). The inspection results reflect the production quality management level of the enterprise. Inspection results are recorded as defective items, and there are 313 articles in the drug production quality management standard (revised in 2010). If the enterprise fails to comply with a certain provision, the degree of non-compliance shall be classified as general defect, major defect and serious defect according to the risk (frequency of occurrence * possibility of occurrence * degree of health hazard to the user). According to the classification of inspection results, if there is one serious defect or more than three major defects, the dependent variable will be set as 1 , that means, the production quality management is not good, and the inspection will not pass. If all of them are general defects or major defects below 3 times, it means that the production quality management is ok. After inspection, the dependent variable is set as 0 .

\subsubsection{Explanatory Variables}

According to the research purpose of this paper, the key explanatory variable of this study is mainly the change frequency of the production management director of the selected sample. However, it is found from other relevant studies that other characteristic variables such as human, machine, material, method, environment and measurement also play a crucial role in the production quality management of enterprises. So, in this study, we have the general characteristics variable, risk management characteristics variable, drug characteristics variable, developmental characteristics variable, management system variables, and control the following variables. In terms of the overall characteristics of the enterprise, we control the output value of the enterprise; On the drug eigenvariables, whether a company produces special medicaments is another control variable; Whether the enterprise's $r \& d$ strategy is innovation is as to control variable of enterprise development. In terms of management system variables, the maintenance cost of the laboratory, the number of SOP of the enterprise and the number of serious deviations of the enterprise are controlled. The values of each factor are shown in Table 1. 
Table 1. Definitions and descriptive statistics of variables in this paper.

\begin{tabular}{|c|c|c|c|c|c|}
\hline Variable Name & Definition & Mean & $\begin{array}{l}\text { Standard } \\
\text { Deviation }\end{array}$ & $\begin{array}{l}\text { Minimum } \\
\text { Value }\end{array}$ & $\begin{array}{l}\text { Maximum } \\
\text { Value }\end{array}$ \\
\hline Logarithm of enterprise output value & $\begin{array}{l}\text { Check the logarithm of the annual output } \\
\text { value of the enterprise }\end{array}$ & 6.7780 & 3.3519 & 0 & 11.7137 \\
\hline Graduate or above in quantity & $\begin{array}{l}\text { The number of employees with a graduate } \\
\text { degree or above }\end{array}$ & 1.1302 & 3.2857 & 0 & 33 \\
\hline $\begin{array}{l}\text { The degree of the enterprise leader is } \\
\text { bachelor }\end{array}$ & One is yes, and zero is no. & 0.2850 & 0.4525 & 0 & 1 \\
\hline $\begin{array}{l}\text { The degree of the enterprise leader is master } \\
\text { or above }\end{array}$ & One is yes, and zero is no. & 0.1402 & 0.3480 & 0 & 1 \\
\hline Change frequency of enterprise principal & $\begin{array}{l}\text { The number of changes of the enterprise } \\
\text { principal in the enterprise }\end{array}$ & 0.4419 & 0.7267 & 0 & 3 \\
\hline $\begin{array}{l}\text { The degree of director of manufacturing } \\
\text { management is college }\end{array}$ & One is yes, and zero is no. & 0.3581 & 0.4806 & 0 & 1 \\
\hline $\begin{array}{l}\text { The degree of director of manufacturing } \\
\text { management is bachelor }\end{array}$ & One is yes, and zero is no. & 0.5070 & 0.5011 & 0 & 1 \\
\hline $\begin{array}{l}\text { The degree of director of manufacturing } \\
\text { management is master }\end{array}$ & One is yes, and zero is no. & 0.0233 & 0.1511 & 0 & 1 \\
\hline $\begin{array}{l}\text { director of manufacturing management } \\
\text { change frequency }\end{array}$ & $\begin{array}{l}\text { The number of changes of director of } \\
\text { manufacturing management in the enterprise }\end{array}$ & 1.0748 & 0.9213 & 0 & 4 \\
\hline $\begin{array}{l}\text { Enterprise development strategy for } \mathrm{r} \& \mathrm{~d} \\
\text { innovation }\end{array}$ & One is yes, and zero is no. & 0.3767 & 0.4857 & 0 & 1 \\
\hline $\begin{array}{l}\text { Annual control cost logarithm of quality } \\
\text { control laboratory }\end{array}$ & $\begin{array}{l}\text { Annual control cost logarithm of quality } \\
\text { control laboratory }\end{array}$ & 2.5396 & 1.2702 & 0 & 6.6214 \\
\hline The number of SOP in an enterprise & The number of SOP in an enterprise & 613.9070 & 661.4971 & 1 & 5500 \\
\hline Significant deviation number & Significant deviation number & 5.0558 & 19.6646 & 0 & 262 \\
\hline
\end{tabular}

Personnel training problems encountered in the implementation of GMP

No personnel training issues were encountered

One is yes, and zero is no.

Personnel training issues are rarely encountered

One is yes, and zero is no.

One is yes, and zero is no.

One is yes, and zero is no.

One is yes, and zero is no.

Personnel training issues are always encountered

Software problems encountered in implementing GMP

Software problems are rarely encountered

Software problems are commonly encountered

Software problems are usually encountered

Software problems are always encountered
One is yes, and zero is no.

One is yes, and zero is no.

One is yes, and zero is no.

One is yes, and zero is no.
0.2419

0.4279

0.1767

0.0279

0.165

0.4292

0

1

$\begin{array}{lll}0.4959 & 0 & 1\end{array}$

$\begin{array}{lll}3823 & 0 & 1\end{array}$

$1651 \quad 0$ 


\section{The Empirical Results}

This paper uses two econometric models to analyze the impact of enterprise size on GMP inspection results. OLS regression is used as the basic model. Since the inspection results can be divided to yes or no, that is, the dependent variable used in this paper is binary variable, we use Logit model as the main econometric model. In the model, enterprise characteristic variables, risk management characteristic variables, drug characteristic variables and development characteristic variables are taken as control variables and incorporated into the econometric equation.

\subsection{Results of OLS Model}

Table 2 is the OLS model measurement regression results of the factors influencing enterprise GMP inspection results, which is the basic model results of this paper. As can be seen from the results in the table, after controlling the enterprise characteristic variables, risk management characteristic variables, drug

Table 2. OLS model regression results.

\begin{tabular}{|c|c|c|c|c|}
\hline Variable & Coef. & Std. Err. & $\mathrm{t}$ & $P>|t|$ \\
\hline Logarithm of enterprise output value & -0.0021 & 0.0083 & -0.2600 & 0.7980 \\
\hline Graduate or above in quantity & -0.0031 & 0.0089 & -0.3500 & 0.7260 \\
\hline The degree of the enterprise leader is bachelor & 0.0233 & 0.0636 & 0.3700 & 0.7150 \\
\hline The degree of the enterprise leader is master or above & -0.0858 & 0.0848 & -1.0100 & 0.3130 \\
\hline Change frequency of enterprise principal & 0.0194 & 0.0367 & 0.5300 & 0.5980 \\
\hline The degree of director of manufacturing management is college & 0.0469 & 0.0899 & 0.5200 & 0.6020 \\
\hline The degree of director of manufacturing management is bachelor & 0.1041 & 0.0867 & 1.2000 & 0.2310 \\
\hline The degree of director of manufacturing management is master & 0.0750 & 0.1919 & 0.3900 & 0.6960 \\
\hline Director of manufacturing management change frequency & $0.0725^{* *}$ & 0.0300 & 2.4200 & 0.0170 \\
\hline Enterprise development strategy for $r \& d$ innovation & 0.0816 & 0.0576 & 1.4200 & 0.1580 \\
\hline Annual control cost logarithm of quality control laboratory & 0.0356 & 0.0223 & 1.6000 & 0.1110 \\
\hline The number of SOP in an enterprise & 0.0000 & 0.0000 & -0.0200 & 0.9810 \\
\hline Significant deviation number & -0.0017 & 0.0014 & -1.2000 & 0.2310 \\
\hline Personnel training issues are rarely encountered & -0.0081 & 0.1023 & -0.0800 & 0.9370 \\
\hline Personnel training issues are commonly encountered & 0.0490 & 0.1020 & 0.4800 & 0.6310 \\
\hline Personnel training issues are usually encountered & 0.1572 & 0.1156 & 1.3600 & 0.1760 \\
\hline Personnel training issues are always encountered & 0.3704 & 0.1918 & 1.9300 & 0.0550 \\
\hline Software problems are rarely encountered & 0.2015 & 0.0903 & 2.2300 & 0.0270 \\
\hline Software problems are commonly encountered & 0.1866 & 0.0932 & 2.0000 & 0.0470 \\
\hline Software problems are usually encountered & 0.2582 & 0.1212 & 2.1300 & 0.0350 \\
\hline Software problems are always encountered & 0.1168 & 0.1566 & 0.7500 & 0.4570 \\
\hline Constant term & 0.0356 & 0.1354 & 0.2600 & 0.7930 \\
\hline
\end{tabular}


characteristic variables and development characteristic variables, the OLS model demonstrated acceptable fit (Coef. $=0.0725, \mathrm{P}<0.05)$. Which shows that the more director of manufacturing management changes, the worse the GMP inspection results are, indicating that the level of drug quality management is also poor. In addition, the more personnel training issues are counted, the worse the GMP inspection results are (Coef. $=0.3704, \mathrm{P}<0.1$ ). If the company is usually encountered software problems, the GMP inspection results are poor (Coef. = $0.2582, \mathrm{P}<0.05)$. Therefore, the hypothesis in this study was confirmed.

\subsection{Results of Logit Model}

Table 3 shows the Logit model regression results of influencing factors of GMP inspection. As can be seen from the results in the table, after controlling the enterprise characteristic variables, risk management characteristic variables, drug characteristic variables and development characteristic variables from the results of the production management director variable, the OLS model demonstrated acceptable fit (Coef. $=0.5245, \mathrm{P}<0.05)$. Which shows that the more director of

Table 3. Logit model regression results.

\begin{tabular}{|c|c|c|c|c|}
\hline Variable & Coef. & Std. rr. & $\mathrm{z}$ & $P>|z|$ \\
\hline Logarithm of enterprise output value & -0.0309 & 0.0636 & -0.4900 & 0.6270 \\
\hline Graduate or above in quantity & -0.0400 & 0.1010 & -0.4000 & 0.6920 \\
\hline The degree of the enterprise leader is bachelor & 0.1499 & 0.4749 & 0.3200 & 0.7520 \\
\hline The degree of the enterprise leader is master or above & -0.8537 & 0.7618 & -1.1200 & 0.2620 \\
\hline Change frequency of enterprise principal & 0.1736 & 0.2652 & 0.6500 & 0.5130 \\
\hline The degree of director of manufacturing management is college & 0.8034 & 0.9233 & 0.8700 & 0.3840 \\
\hline The degree of director of manufacturing management is bachelor & 1.2311 & 0.8905 & 1.3800 & 0.1670 \\
\hline The degree of director of manufacturing management is master & 1.4493 & 1.5285 & 0.9500 & 0.3430 \\
\hline Director of manufacturing management change frequency & $0.5245^{* *}$ & 0.2166 & 2.4200 & 0.0150 \\
\hline Enterprise development strategy for $\mathrm{r} \& \mathrm{~d}$ innovation & 0.7254 & 0.4301 & 1.6900 & 0.0920 \\
\hline Annual control cost logarithm of quality control laboratory & 0.3219 & 0.1789 & 1.8000 & 0.0720 \\
\hline The number of SOP in an enterprise & 0.0000 & 0.0003 & 0.0200 & 0.9810 \\
\hline Significant deviation number & -0.0123 & 0.0128 & -0.9600 & 0.3360 \\
\hline Personnel training issues are rarely encountered & 0.0437 & 0.7705 & 0.0600 & 0.9550 \\
\hline Personnel training issues are commonly encountered & 0.3910 & 0.7882 & 0.5000 & 0.6200 \\
\hline Personnel training issues are usually encountered & 1.3613 & 0.8690 & 1.5700 & 0.1170 \\
\hline Personnel training issues are always encountered & 2.1780 & 1.2324 & 1.7700 & 0.0770 \\
\hline Software problems are rarely encountered & 1.5273 & 0.6916 & 2.2100 & 0.0270 \\
\hline Software problems are commonly encountered & 1.2981 & 0.6686 & 1.9400 & 0.0520 \\
\hline Software problems are usually encountered & 1.8223 & 0.9299 & 1.9600 & 0.0500 \\
\hline Software problems are always encountered & 0.7778 & 1.0681 & 0.7300 & 0.4660 \\
\hline Constant term & -3.5141 & 1.2089 & -2.9100 & 0.0040 \\
\hline
\end{tabular}


manufacturing management changes, the worse the GMP inspection results are, indicating that the level of drug quality management is also poor. In addition, the more personnel training issues are counted, the worse the GMP inspection results are (Coef. $=2.1780, \mathrm{P}<0.1)$. If the company is usually encountered software problems, the GMP inspection results are undesirable (Coef. $=1.8223, \mathrm{P}=$ 0.05). Therefore, the hypothesis in this study was confirmed.

\section{Conclusions}

Although man, machine, material, method, environment, and measurement, as an analysis tool for quality management, are widely used to analyze pharmaceutical production quality, the most important factor is man in the quality management of pharmaceutical production. As specific performer in the enterprise operation and as a research emphasis in all management theories, how to effectively manage personnel is the biggest difficulty in production management.

In view of the background of the booming medical market in China, personnel changes in medical industry are inevitable. In order to get better treatment and broader development space, medical workers often seek new job opportunities. In addition to the employee's voluntary turnover, employees may be fired or changed by enterprises. For example, in order to adapt to the changing market, enterprises carry out internal reform and change company organization, which is also an important reason for personnel changes in medical industry. Therefore, a variety of factors can lead to personnel changes. As an employee in pharmaceutical company, the reasons for the change of director of manufacturing management can be divided into two types according to the different situation of employees to leave the organization, namely Non-binding departure and binding departure. Non-binding departure refers to the employee's voluntary behavior to leave the organization, which mainly includes the normal change of tenure caused by retirement, age, death and expiration of term of office. Binding departure refers to the behavior of employees who are forced to leave the organization initiated by the organization, including personnel changes under internal and external constraints such as poor performance, changes in management structure and so on. However, frequent changes at the grass-roots level or executive-management level will bring high risks to the enterprise and have an adverse impact on enterprise culture, management system, and the continuation and preservation of archival resources, which ultimately have an adverse impact on the quality of products. As the actual operator and direct manager of the production system, director of manufacturing management of pharmaceutical production enterprises plays an important role in the production process, and it also has the same significant impact on other aspects like human, machine, material, law, and environment. The frequent change of director of manufacturing management leads to the instability of the pharmaceutical production system, poor consistency of production, and lake of adequate quality assurance. Eventually, produced pharmaceutical goods are of poor quality and competitiveness in the 
market. Secondly, it also brings about the poor operation of drug production system, and finally affects the product quality.

According to the research results of this paper, there is a correlation between the change frequency of director of manufacturing management and the GMP inspection results. The more director of manufacturing management changes, the lower the level of drug production management. We suggest, from the perspective of supervision, the change of director of manufacturing management can be used as an indicator of daily supervision. We should pay attention to the enterprises with frequent changes of director of manufacturing management by increasing the inspection frequency and spot check frequency, so as to find unqualified products as soon as possible. The enterprise with a stable director of manufacturing management, beneficial to its high standardization, can appropriately reduce the inspection frequency to save supervision costs and achieve the best supervision effect. For enterprises with stable production management principals, encourage them to participate in industry affairs to promote their experience based on self-discipline sense. In view of the importance of this position in product quality, personnel in this position can also be trained by the food and drug administration to improve their awareness of ensuring the pharmaceutical production quality and the ability of execution duty. The deficiencies of this study are as follows. Firstly, due to the low availability of data of pharmaceutical enterprises and the lack of relevant similar studies, there are few similar literatures for this study to refer to. However, this also reflects the value of this study, filling the research gap. Secondly, the sample size selected in this study is too small, so the research results may be unstable and lack of reliability. Therefore, the follow-up research needs to increase the sampling survey of other typical cities in order to enhance the robustness of the research results.

What's more, from the perspective of management, enterprises should pay attention to the reasons for the departure of director of manufacturing management, constantly improve the salary and career development space of director of manufacturing management, or reduce the adjustment of senior executive within the enterprise, so as to minimize the change of director of manufacturing management and maintain the stability of production.

\section{Conflicts of Interest}

The authors declare no conflicts of interest regarding the publication of this paper.

\section{References}

[1] (2010) Standards for Quality Control of Drug Production (2010 Edition): Decree No. 79 of the Ministry of Health.

[2] ICH (2005) Pharmaceutical Quality System Q9. ICH, Geneva. https://www.ich.org/fileadmin/Public Web Site/ICH Products/Guidelines/Quality /Q9/Step4/Q9 Guideline.pdf

[3] ICH (2008) Pharmaceutical Quality System Q10. ICH, Geneva. 
http://www.ich.org/fileadmin/Public Web Site/ICH Products/Guidelines/Quality/ Q10/Step4/Q10 Guideline.pdf

[4] Tao, Q.H. (2015) China Pharmaceutical Economic Operation Analysis and "13th Five-Year" Trend Forward. China Food \& Drug Administration Magazine, No. 12, 28-32.

[5] (2004) Measures for Supervision and Administration of Drug Production (Bureau Decree No. 14). China Pharmaceutical Intelligence, No. 6, 1-7.

[6] Burton, T. and Walsh, D. (1998) The Role of Personnel in Change Processes: Introducing the "Charabanc of Change" Typology. Strategic Change, 7, 407-420. https://doi.org/10.1002/(SICI)1099-1697(1998110)7:7<407::AID-ISC400>3.0.CO;2$\underline{\mathrm{F}}$

[7] Currie, G. and Procter, S. (1998) The Role of the Personnel Department in the Management of Change in the UK NHS. Strategic Change, 7, 375-386. https://doi.org/10.1002/(SICI)1099-1697(1998110)7:7<375::AID-ISC393>3.0.CO;2$\underline{2}$

[8] Stewart, A.J. and Diebold, J. (2017) Turnover at the Top: Investigating Performance-Turnover Sensitivity among Nonprofit Organizations. Public Performance \& Management Review, 40, 741-764. https://doi.org/10.1080/15309576.2017.1340900

[9] Alabdullah, T.T.Y., Yahya, S., Nor, M.I., et al. (2016) An Investigation of Corporate Governance from a New Perspective: Examining the Financial Performance of Companies and the Impact of Executive Change. Corporate Board: Role, Duties \& Composition, 12, 53-69. https://doi.org/10.22495/cbv12i1art6

[10] Han, W. (2015) Research on the Relationship between Executive Change and Earnings Management of Gem Listed Companies.

[11] Zhang, W. (2016) Research on the Influence of Executive Change on the Growth of Listed Retail Enterprises.

[12] Wei, J. (2013) Research on the Relationship between Executive Change and Company Performance.

[13] Zhu, M. (2018) Research on Optimization of Pharmaceutical Production Quality Management System of a Company.

[14] Liu, Z. (2017) Research on the Construction of Standardized Indicators and Parameters for Daily Supervision of Drug Production in Beijing.

[15] Qiao, W.L. (2016) Control and Management of Changes by Quality Managers in Pharmaceutical Manufacturers. Chinese Medical Science, 6, 94-96. 